\title{
Peculiarities of the reactions between early lanthanide(III) ions and an anionic porphyrin
}

\author{
Melitta Patrícia Kiss, Muhammad Imran, Csanád Szentgyörgyi, Zsolt Valicsek* and Ottó \\ Horváth \\ Department of General and Inorganic Chemistry, Institute of Chemistry, Faculty of Engineering, \\ University of Pannonia, P.O.B. 158, Veszprém H-8201, Hungary
}

\begin{abstract}
Insertion of early lanthanide(III) ions into the coordination cavity of porphyrins is a slow and complicated process in aqueous solution, originating from the stability of their aqua complexes and their possible oligomerization. The presence of potential axial ligands can accelerate the coordination of the first porphyrin, but it can hinder the connection of a further porphyrin. Lanthanide ions may coordinate not only to the pyrrolic nitrogens of porphyrins but, under kinetic control, also to the peripheral substituents possessing $\mathrm{O}$-donor atoms. In the case of such anionic porphyrins, the coordination position of metal ions can be influenced by the change of temperature.
\end{abstract}

Keywords: simultaneous metal and ligand control, out-of-plane metalloporphyrins, early lanthanide(III) ions, axial enhancement or hindrance, tail-to-tail oligomerization.

\footnotetext{
* Corresponding author. Tel.: +36 (88) 624 431; fax: +36 (88) 624548 (Z. Valicsek).

E-mail addresses: valicsek@ vegic.uni-pannon.hu (Z. Valicsek), kiss.melitta.p@ gmail.com (M.P. Kiss), muhammadimranum@ yahoo.com (M. Imran), fehron@ gmail.com (C. Szentgyörgyi), otto@ vegic.uni-pannon.hu (O. Horváth).
} 
Metalloporphyrins are the strongest ultraviolet-visible light absorbing materials in nature, therefore they are also called as "the pigments of the life" [1]. Their formation reactions belong to the most important processes from both bioinorganic and analytical points of view. Nevertheless, the mechanism of the metal ion's insertion into the coordination cavity has not been completely elucidated yet [2]. Porphyrins are peculiar ligands in the respect of complexation because, due to their planar, cyclic, rigid, aromatic, tetradentate, as well as protonated structure, the formation of metalloporphyrins is a special ligand-controlled reaction [3]. As a consequence of the coordination cavity's limited size, the metal ions, depending on their radius, can occupy an in-plane (IP) or an out-of-plane (OOP or SAT=sitting-atop) position [4].

The formation of the complexes with large metal ions are usually at least two-orders-ofmagnitude faster than those with medium-scale ones, what can be explained with the higher chance for the formation of end-product through intermediate $\left\{\mathrm{H}_{2}-\mathrm{Porph}-\mathrm{M}\right\}^{\mathrm{m}+}$ (i-SAT) complexes, in which the metal ion and the pyrrolic protons are simultaneously coordinated to the porphyrin cavity. This two orders of magnitude difference between in-plane and out-ofplane complexes is manifested also in their dissociation rate constants, i.e. in their lability, which are proportional to the radius of the metal ions $[5,6]$.

The formation of metalloporphyrins in aqueous solution (or in other polar solvents) is an equilibrium reaction, owing to the higher activity and mobility of metal ions than in nonpolar solvents [3]. This process can be characterized by the apparent stability constant ( $\beta$ ' $x: y$ in Eqs. 1-2), which includes the proton concentration, determined mainly in buffered solutions. $\mathrm{H}_{2} \mathrm{TSPP}^{4-}$ \{anionic 5,10,15,20-tetrakis(4-sulfonatophenyl)porphyrin, also abbreviated as $\mathrm{H}_{2} \mathrm{P}^{4}$ in our work is the most widely used water-soluble porphyrin [7], besides its negative charge enhances the coordination of positively charged metal ions $[5,6,8]$.

$$
\begin{gathered}
\mathrm{x} \mathrm{M}^{\mathrm{z+}+\mathrm{y} \mathrm{H}_{2} \mathrm{TSPP}^{4-}} \Leftrightarrow \mathrm{M}_{\mathrm{x}}(\mathrm{TSPP})_{\mathrm{y}}{ }^{\mathrm{xz}-6 \mathrm{y}}+2 \mathrm{y} \mathrm{H}^{+} \\
\beta_{\mathrm{x}: \mathrm{y}}^{\prime}=\frac{\beta_{\mathrm{x}: \mathrm{y}}}{\left[\mathrm{H}^{+}\right]^{2 \mathrm{y}}}=\frac{\left[\mathrm{M}_{\mathrm{x}}(\mathrm{TSPP})_{\mathrm{y}}{ }^{\mathrm{xz}-6 \mathrm{y}}\right]}{\left[\mathrm{M}^{\mathrm{z+}}\right]^{\mathrm{x}}\left[\mathrm{H}_{2} \mathrm{TSPP}^{4-}\right]^{\mathrm{y}}}
\end{gathered}
$$

Due to the out-of-plane position, a larger metal ion can simultaneously coordinate to the cavitiy of two macrocycles, and, reversely, two metal ions can connect to one ligand, resulting in the formation of so-called sandwich complexes with various compositions [9-12]. In these complexes, the strength of $\pi-\pi$ interaction depends on the distance between the macrocycles, which is strongly influenced by the size of the metal center. Therefore, lanthanide(III) ions offer good opportunities to examine this dependence due to the fine tuning of the out-of-plane distances, utilizing the well-known lanthanide contraction. From optical and photophysical aspects, porphyrins are able to efficiently sensitize the near-infrared luminescence of lanthanide ions, which can be widely applied, e.g. in optical telecommunication, spectral conversion of solar energy, and biomedical optical imaging [13-17]. From coordination chemical aspects, lanthanide(III) ions incline to higher coordination number (8-12), which can be manifested in their aforementioned sandwich complexes [18-20]. As a consequence of their strong susceptibility to higher coordination numbers, the investigation of their monoporphyrins is complicated: another multidentate, but $\mathrm{O}$-donor ligand must be applied to hinder the coordination of the second porphyrin to the metal ion [13-17, 21].

In this work, we studied the reaction between the mentioned anionic porphyrin $\left(\mathrm{H}_{2} \mathrm{TSPP}^{4-}\right.$ ) and early lanthanide(III) ions ( $\mathrm{Ln}=\mathrm{La}, \mathrm{Ce}, \mathrm{Nd}, \mathrm{Sm})$ under various conditions. The presence or absence of acetate ion as bidentate, $\mathrm{O}$-donor ligand proved to be a key factor from the viewpoint of the metal-porphyrin interactions in our systems. Insertion of these larger metal ions into the porphyrin cavity can be spectrophotometrically followed due to the redshifts of UV-Vis, intraligand $\pi \pi^{*}$ absorption bands, similarly to other typical OOP complexes, which display "common" absorption properties in both region of visible spectrum [5, 6, 11, 22-25]: B- or 
Soret-bands at about $350-500 \mathrm{~nm}$ and Q-bands at 500-750 nm. Instead of the electronic, the steric effect of a metal ion in OOP position has a stronger influence on the absorption bands due to the dome-distortion of the macrocycle. In arylated porphyrins, the distortion can result in the extension of delocalization by the twisting of aryl substituents from almost perpendicular orientation closer to the mean-plane of porphyrin [5, 26].

Owing to the very high molar absorbance of the porphyrin $\left\{\varepsilon\left(\mathrm{H}_{2} \mathrm{TSPP}^{4-}\right) 413 \mathrm{~nm}=4.66 \times 10^{5}\right.$ $\left.\mathrm{M}^{-1} \mathrm{~cm}^{-1}[27]\right\}$, its concentration may be in the order of $10^{-6} \mathrm{M}$ in the generally used 1-cmpathlength cuvette. However, the lanthanide salts must be applied in 3-4 orders of magnitude excess to shift the equilibrium towards the complex formation (Eq. 1) [20]. Lanthanide(III) ions are hard Lewis acids, due to the classification of Pearson, therefore, their insertion into the coordination cavity of the tetradentate, $\mathrm{N}$-donor porphyrin ligand is a slow and complicated process in aqueous solution, originating partly from the strong bond of the solvent water molecules to the metal ions [14, 28-30]. This kinetic barrier is vanquishable, e.g. by heating: in our case to $\sim 60^{\circ} \mathrm{C}$; hence, the required time to reach the equilibrium is shortened to half a day (Fig. 1.a). The presence of bidentate, O-donor acetate ion enhances the coordination of the first porphyrin ligand, due to its trans effect, but it hinders the connection of a further porphyrin, i.e. the formation of bisporphyrins, because it remains on the lanthanide(III) ion in axial position. While its axial coordination to a lanthanide(III)-monoporphyrin, exchanging two water molecules, has negligible effect on the absorption bands (Fig. 1.a, b and Fig. S1), in contrast with the typical redshift in the case of the axial ligation of post-transition metalloporphyrins $[25,31,32]$. However, it increases the stability of the monoporphyrin complex with half order of magnitude, due to its trans effect, e.g. in the case of lanthanum(III): $\operatorname{lgß}{ }^{\prime}{ }_{1: 1}[(\mathrm{Ac}) \mathrm{LaP}]^{4-}=3.8$ and $\lg \beta_{1: 1}[\mathrm{LaP}]^{3-}=3.3[20]$.
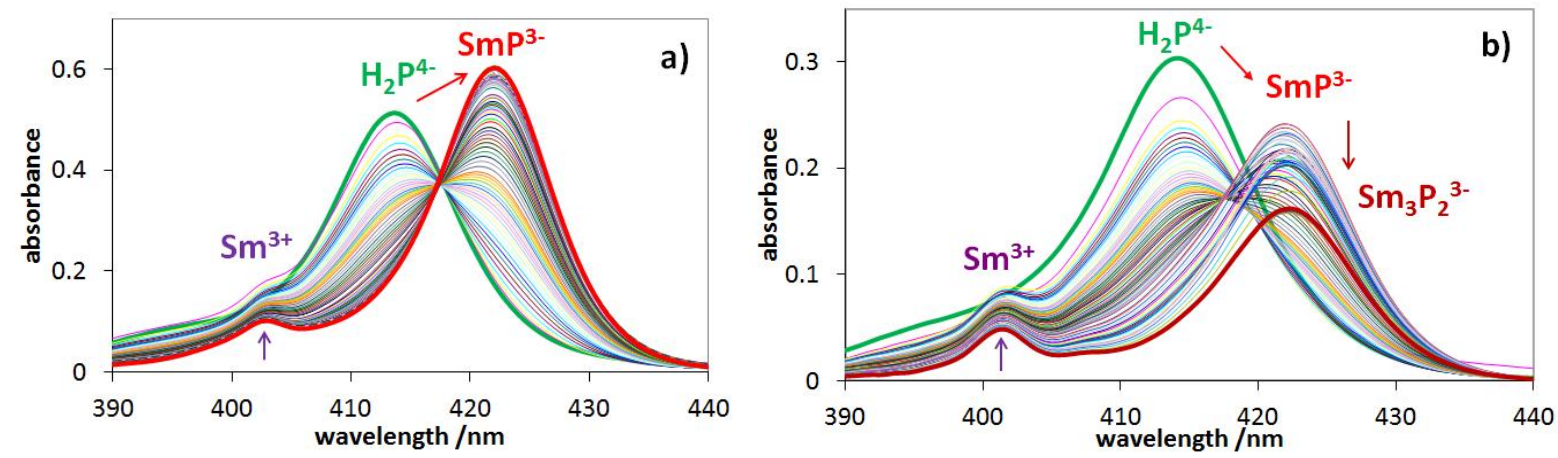

Fig. 1. Soret-absorption spectral changes during the reaction (in 1-cm optical length cuvette) between $1.0 \times 10^{-6} \mathrm{M} \mathrm{H}_{2} \mathrm{P}^{4-}$ and $1.2 \times 10^{-2} \mathrm{M} \mathrm{Sm}^{3+}\left(\right.$ at $65^{\circ} \mathrm{C}$ ),

a) in the presence of $1 \mathrm{M} \mathrm{NaAc} / \mathrm{HAc}$ buffer $(\mathrm{pH}=6)$, reaction total time: $15 \mathrm{~h}$.

b) in the presence of $1 \mathrm{M} \mathrm{NaClO}_{4}$, reaction total time: $56 \mathrm{~h}$.

If non-coordinating perchlorate ion is applied to adjust the ionic strength, lantanide bisporphyrin can form too, which has slightly further redshifted and broadened absorption bands, compared to those of the monoporphyrin (Fig. 1.b and Fig. S1). As a consequence of this small difference between the molar absorption spectra of the metallo-mono- and bisporphyrin, the formation of the latter is indicated only by the decrease of absorbances at nearly the same wavelengths (421 nm on Fig. 1.b). Furthermore, the reaction decelerates: 56 hours is not enough to reach the equilibrium (Fig. 1.b and Fig. S2), while in the presence of acetate $\sim 8$ hours proved to be sufficient (Fig. 1.a) at the same concentrations, ionic strength, $\mathrm{pH}$, and temperature.

During a deeper investigation of this phenomenon, low $(0.01 \mathrm{M})$ acetate concentration was enough to totally hinder the formation of bisporphyrin. In this concentration range the partial molar fraction of monoacetato-lanthanide(III) complexes, [LnAc $]^{2+}$, began to increase (Eq. 3). Simultaneously, the apparent (calculated for the total, inital metal ion concentration) 
formation rate constant of the porphyrin complex decreases; the acceleration is observable only at somewhat higher acetate concentration (Fig. 2), together with the appearance of diacetato complexes, $\left[\mathrm{LnAc}_{2}\right]^{+}$. The coordination number may change from 9 (in the inital nonaaqua complex, which is characteristic for the early lanthanide ions [28]) to 8, and this latter one fits better to the insertion into the porphyrin's cavity, resulting in the SAPR-8 (square antiprism) or CU-8 (cubic) coordination polyhedron [10, 13]. Finally, at higher acetate coordination, the formation of triacetato-lanthanide(III) complex, [LnAc 3 , can slightly decelerate again the insertion into the macrocycle, as a consequence of the steric hindrance of the third, bidentate ligand.



Fig. 2. Change of the apparent formation rate constant of samarium(III)monoporphyrin with the increase of acetate concentration.

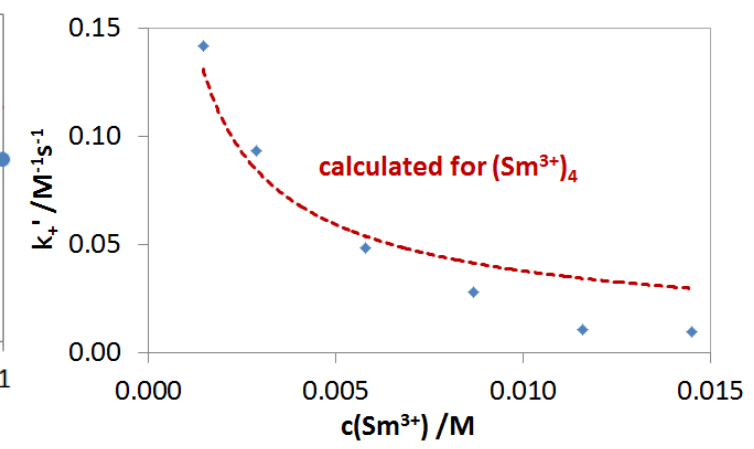

Fig. 3. Decrease of the apparent formation rate constant of samarium(III)monoporphyrin with the increase of initial $\mathrm{Sm}^{3+}$ concentration. (Calculated data from the assumption of tetramers.)

On the basis of our experiments, the coordination of potential axial ligands to a lanthanide ion may result in steric, rather than in electronic effects on the formation of the metalloporphyrin. The latter ones as trans-effects (acceleration of the solvent molecule's exchange reaction in the opposite coordination position) were mainly referred to in the case of transition and posttransition metal ions in the literature [33, 34].

A large difference can be observed between post-transition metal and lanthanide ions during the determination of the reaction order for them. The rate-determining step in the insertion of the former ones was found to be associative, first order for both the metal ion and the porphyrin. Insertion of post-transition metal ions usually follows the same, typically ligandcontrolled mechanism $[2,3,5,8]$, on the basis of the discovered isokinetic relationships $[5,35]$. However, the reaction between the lanthanide(III) ions as hard acids and the softer, $\mathrm{N}$-donor porphyrin ligand shows a simultaneous metal control that originates not only from the stability of their (nona)aqua complexes. The other reason is that the lanthanide ions have to be applied in 3-4 orders of magnitude excess $\left(10^{-3}-10^{-2} \mathrm{M}\right)$, compared to the porphyrin concentration, to push the equibrium towards the complex formation. In such a concentration, lanthanide(III) ions compose oligomers through the counter-anion or hydroxide bridges in aqueous solution $[36,37]$. Therefore, the pre-dissociation of these oligomers is required for the formation of porphyrin complexes because only the monomer lanthanide ion is able to insert into the coordination cavity. Consequently, the reaction rate, together with the partial molar fraction of lanthanide monomer (Eqs. 4-5), decreases with the increase of the initial metal concentration (Fig. 3). Hence, negative (and diminishing) fractions can be apparently determined as reaction orders from the method of initial rates.

$$
\begin{aligned}
& H_{2} P^{4-}+\left(\operatorname{Ln}^{3+}\right)_{z} \Leftrightarrow L n^{I I I} P^{3-}+\left(L n^{3+}\right)_{z-1}+2 H^{+} \\
& k_{+}^{(\text {oligomer })}=\Phi_{1}^{\text {oligomer }}\left(\operatorname{Ln}^{3+}\right) \times k_{+}\left(\left(L n^{3+}\right)_{1}\right)
\end{aligned}
$$


As a further consequence of the Pearson-type hard character of lanthanide(III) ions, they can coordinate rather to the peripheral substituent of porphyrin (e.g. to the ionic group ensuring water-solubility), if it possesses similarly hard O-donor atom (e.g. carboxy-phenyl), than to the pyrrolic nitrogens $[17,38,39]$. However, this phenomenon was previously unknown for the sulfonato-phenyl porphyrin. At lower temperatures (and in the absence of acetate), the position of the free-base porphyrin's absorption bands did not change; only their intensities were approximately dimidiated (Fig. 4.a). Under this kinetic control, the early lanthanide(III) ions were not able to coordinate into the cavity, rather to the sulfonate groups; resulting in the formation of the free-base ligands' tail-to-tail oligomer (Fig. 4.b). Only under thermodynamic control, i.e. at higher temperatures, can coordinate the metal ion also, or rather, to the four pyrrolic nitrogens; resulting in the formation of typical metalloporphyrin complexes (Fig. 5).

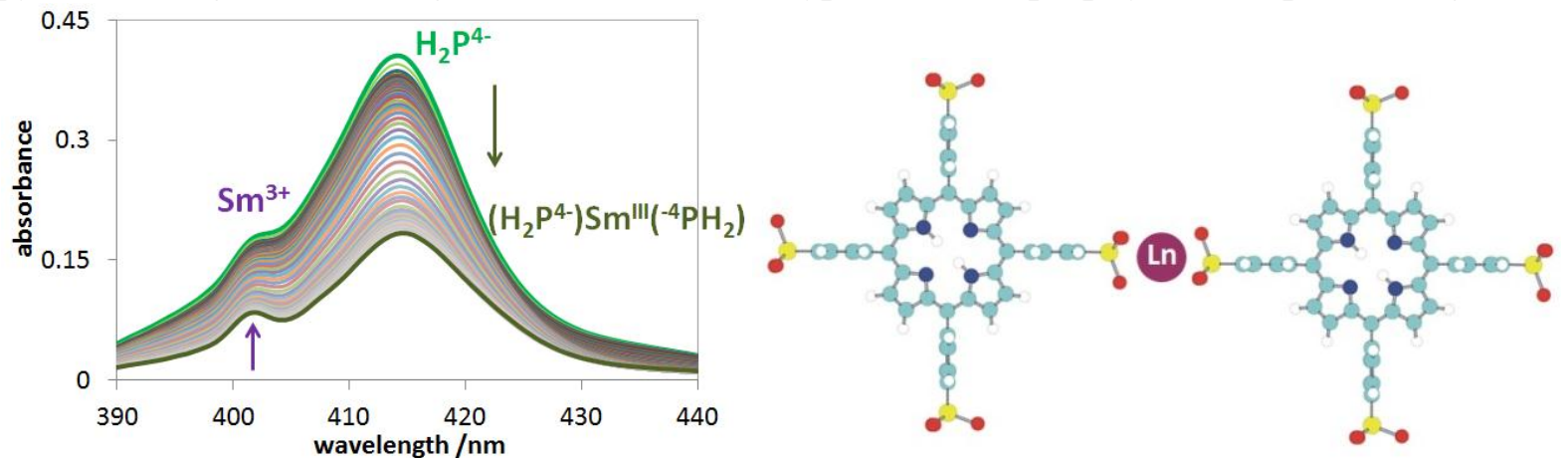

Fig. 4.a) Soret-absorption spectral changes at $25^{\circ} \mathrm{C}$, reaction total time: $15 \mathrm{~h}$.

b) Structure of the anionic porphyrin's tail-to-tail dimer, connected by a lanthanide(III) ion.



Fig. 5. Temperature dependence (using Eyring-Polányi equation) of the rate constant of reaction between $1.0 \times 10^{-6} \mathrm{M} \mathrm{H}_{2} \mathrm{P}^{4-}$ and $1.2 \times 10^{-2} \mathrm{M} \mathrm{Sm}^{3+}$ in the presence of $1 \mathrm{M} \mathrm{NaClO}_{4}$ $(\mathrm{pH} \approx 6)$.

After the discovery of the possible coordination bonds between lanthanide ions and sulfonato substituents, the formation of lanthanide bisporphyrins, in the absence of acetate, may be imagined as a tail-to-tail dimerization of two metallo-monoporphyrin complexes through a metal bridge, similarly to the free-base porphyrins (Fig. 4.b), and deviating from the head-tohead connection as in the case of sandwich complexes. This assumption may be confirmed by the large similarities between the absorption spectra (Fig. 1.b and Fig. S1) as well as the single t1 fluorescence spectra of these early lanthanide(III)-mono- and bisporphyrin complexes. These spectral similarities and comparable fluorescence quantum yields may only originate from very weak $\pi-\pi$ interactions between the macrocycles. If these interactions may be stronger, the absorption bands should show much larger redshifts and hyperchromicities, and the fluorescence should be much weaker, nearly disappear. This was manifested in the case of the (parallel) head-to-tail dimer of the protonated porphyrin, $\left(\mathrm{H}_{4} \mathrm{TSPP}^{2-}\right)_{2}$ [40], and of the bisporphyrins of mercury(II) ion: (parallel) head-to-tail $\mathrm{Hg}_{2}$ (TSPP $_{2}{ }^{8-}$ and typical head-to- 
head $\mathrm{Hg}^{\mathrm{II}} 3$ (TSPP) ${ }_{2}{ }^{6-}[5,11]$. However, other special types of aggregation (e.g. perpendicular head-to-tail) among lanthanide-monoporphyrins may occur, too, chiefly at higher porphyrin concentration.

A more profound investigation of the reactions between lanthanide ions and watersoluble porphyrins is in progress to separate the potential electronic and steric effects of the axial ligands, directly on the coordination of lanthanide ions to the cavity or the periphery of porphyrins, and indirectly, through the influence of oligomerization.

Supplementary data (Fig. S1, S2) associated with this article can be found, in the online version.

\section{Acknowledgments}

This work was supported by the Hungarian Scientific Research Fund (NN107310), the Hungarian Government and the European Union, with the co-funding of the European Social Fund (TÁMOP-4.2.2.A-11/1/KONV-2012-0071), and the Austrian-Hungarian Action Foundation (86öu3).

\section{References}

1. A.R. Betters by, C.J.R. Fookes, G.W.J. Matcham, E. McDonald, Biosynthesis of the pigments of life: formation of the macrocycle, Nature (London) 285 (1980) 17-21.

2. S. Funahashi, Y. Inada, M. Inamo, Dynamic study of metal-ion incorporation into porphyrins based on the dynamic characterization of metal ions and on sitting-atop complex formation, Anal. Sci. 17 (2001) 917-927.

3. P. Hambright, The coordination chemistry of metalloporphyrins, Coord. Chem. Rev. 6 (1971) 247-268.

4. J. Barnes, G. Dorough, Exchange and replacement reactions of $\alpha, \beta, \gamma, \delta$-tetraphenyl-metalloporphins, J. Am. Chem. Soc. 72 (1950) 4045-4050.

5. Z. Valicsek, O. Horváth, Application of the electronic spectra of porphyrins for analytical purposes: the effects of metal ions and structural distortions, Microchem. J. 107 (2013) 47-62.

6. O. Horváth, R. Huszánk, Z. Valicsek, G. Lendvay, Photophysics and photochemsitry of kinetically labile, water-soluble porphyrin complexes, Coord. Chem. Rev. 250 (2006) 1792-1803.

7. M. Biesaga, K. Pyrzynska, M. Trojanowicz, Porphyrins in analytical chemistry. A review, Talanta 51 (2000) 209-224.

8. M. Inamo, A. Tomita, Y. Inagaki, N. Asano, K. Suenaga, M. Tabata, S. Funahashi, Equilibria, kinetics and mechanism of complexation of 5,10,15,20-tetrakis(4-sulphonatophenyl)porphyrin and its N-methylated derivate with cadmium(II) and zinc ions in auqueous solution at various temperatures and pressures. Effects of metal ion size and porphyrin ring deformation on metal ion incorporation, Inorg. Chim. Acta 256 (1997) 77 85.

9. J.W. Buchler, A. Decian, J. Fischer, M. Kihnbotulinski, H. Paulus, R. Weiss, Metal-complexes with tetrapyrrole ligands 40. Cerium(IV) bis (octaethylporphyrinate) and dicerium(III) tris(octaethylporphyrinate) Parents of a new family of lanthanoid double-decker and triple-decker molecules, J. Am. Chem. Soc. 108 (1986) 3652-3659.

10. G. Ricciardi, A. Rosa, E.J. Baerends, S.A.J. van Gisbergen, Electronic Structure, Chemical Bond, and Optical Spectra of Metal Bis(porphyrin) Complexes: A DFT/TDDFT Study of the Bis(porphyrin)M(IV) (M ) Zr, Ce, Th) Series, J. Am. Chem. Soc. 124 (2002) 12319-12334.

11. Z. Valicsek, G. Lendvay, O. Horváth, Equilibrium, photophysical, photochemical and quantum chemical examination of anionic mercury(II) mono- and bisporphyrins, J. Phys. Chem. B. 112 (2008) 14509-14524.

12. Z. Valicsek, G. Lendvay, O. Horváth, Equilibrium, photophysical, photochemical and quantum chemical examination of anionic mercury(I) porphyrins, J. Porph. Phthal. 13 (2009) 910-926.

13. G. Knör, A. Strasser, Coexisting intraligand fluorescence and phosphorescence of hafnium(IV) and thorium(IV) porphyrin complexes in solution, Inorg. Chem. Commun. 5 (2002) 993-995.

14. H. He, A.G. Sykes, D. Galipeau, S. Weng Ng, M. Ropp, Crystallography and photoluminescence properties of b-diketonate monoporphyrinate ytterbium(III) complexes, Inorg. Chem. Commun. 11 (2008) 1051-1053.

15. H. He, A.G. Sykes, Facile preparation of neutral monoporphyrinate lanthanide complexes with strong nearinfrared emission, Inorg. Chem. Commun. 11 (2008) 1304-1307.

16. H. He, Near-infrared emitting lanthanide complexes of porphyrin and BODIPY dyes, Coord. Chem. Rev. 273 (2014) 87-99.

17. V. Bulach, F. Sguerra, M.W. Hosseini, Porphyrin lanthanide complexes for NIR emission, Coord. Chem. Rev. 256 (2012) 1468-1478. 
18. J. Jiang, M. Bao, L. Rintoul, D.P. Arnold, Vibrational spectroscopy of phthalocyanine and naphthalocyanine in sandwich-type (na)phthalocyaninato and porphyrinato rare earth complexes, Coord. Chem. Rev. 250 (2006) 424-448.

19. X. Zhang, Y. Chen, A sandwich mixed (phthalocyaninato) (porphyrinato) europium triple-decker: Balancedmobility, ambipolar organic thin-film transistor, Inorg. Chem. Commun. 39 (2014) 79-82.

20. Z. Valicsek, G. Eller, O. Horváth, Equilibrium, photophysical and photochemical examination of anionic lanthanum(III) mono- and bisporphyrins: the effects of the out-of-plane structure, Dalton Trans. 41 (2012) 13120-13131.

21. G. Knör, A. Strasser, Enhanced photoreactivity of zirconium(IV) and hafnium(IV) porphyrin complexes promoted by water molecules, Inorg. Chem. Commun. 2005, 8, 471-473.

22. O. Horváth, Z. Valicsek, A. Vogler, Unique photoreactivity of mercury(II) 5,10,15,20-tetrakis (4sulfonatophenyl)porphyrin, Inorg. Chem. Commun. 7 (2004) 854-857.

23. G. Harrach, Z. Valicsek, O. Horváth, Water-soluble silver(II) and gold(III) porphyrins: the effect of structural distortion on the photophysical and photochemical behavior, Inorg. Chem. Commun. 14 (2011) 1756-1761.

24. O. Horváth, Z. Valicsek, G. Harrach, G. Lendvay, M.A. Fodor, Spectroscopic and photochemical properties of water-soluble metalloporphyrins of distorted structure, Coord. Chem. Rev. 256 (2012) 1531-1545.

25. Z. Valicsek, O. Horváth, G. Lendvay, I. Kikaš, I. Škorić, Formation, photophysics, and photochemistry of cadmium(II) complexes with 5,10,15,20-tetrakis(4-sulfonatophenyl)porphyrin and its octabromo derivative: the effects of bromination and the axial hydroxo ligand, J. Photochem. Photobiol. A. 218 (2011) 143-155.

26. J.A. Shelnutt, X.-Z. Song, J.-G. Ma, S.-L. Jia, W. Jentzen, C.J. Medforth, Nonplanar porphyrins and their significance in proteins, Chem. Soc. Rev. 27 (1998) 31-41.

27. M. Tabata, K. Ozutsumi, Equilibrium and EXAFS studies of mercury(II) porphyrin in aqueous solution, Bull. Chem. Soc. Jpn. 65 (1992) 1438-1444.

28. Y. Yamaguchi, M. Nomura, H. Wakita, H. Ohtaki, An extended x-ray absorption fine structure study of aqueous rare earth perchlorate solutions in liquid and glassy states, J. Chem. Phys. 89 (1988) 5153-5159.

29. L. Helm, A.E. Merbach, Water exchange on metal ions: experiments and simulations, Coord. Chem. Rev. 187 (1999) $151-181$.

30. S. Haye, P. Hambright, Acid solvolys is kinetics of lanthanide porphyrins, J.C.S. Chem. Commun. (1988) 666668.

31. Y. Feng, S.-L. Ong, J. Hu, W.-J. Ng, Synthesis and characterization of [Ga(TPP)H] (TPP=tetraphenylporphyrinato), Inorg. Chem. Commun. 6 (2003) 466-468.

32. G. Szintay, A. Horváth, Temperature dependence study of five-coordinate complex formation of zinc(II) octaethyl and tetraphenylporphyrin, Inorg. Chim. Acta, 310 (2000) 175-182.

33. P. Hambright, P.B. Chock, Metal-porphyrin interaction III. A dissociative-interchange mechanism for metal ion incorporation into porphyrin molecules, J. Am. Chem. Soc. 96 (1974) 3123-3131.

34. K. Okada, A. Sumida, R. Inagaki, M. Inamo, Effect of the axial halogen ligand on the substitution reactions of chromium(III) porphyrin complex, Inorg. Chim. Acta, 392 (2012) 473-477.

35. J. Reid, P. Hambright, Kinetics of cadmium porphyrin-zinc ion electrophilic exchange reactions: An is okinetic relationship, Inorg. Chim. Acta (Bioinorg. Chem. Letter) 33 (1979) L135-L136.

36. V.G. Solomonik, A.N. Smirnov, Structure and energy stability of lanthanum and lutetium trihalide dimer molecules, J. Struct. Chem. 46 (2005) 973-978.

37. A. Mech, M. Karbowiak, T. Lis, J. Drozdzynski, Monomeric, dimeric and polymeric structure of the uranium trichloride hydrates, Polyhedron 25 (2006) 2083-2092.

38. S. Lipstman, S. Muniappan, S. George, I. Goldberg, Framework coordination polymers of tetra(4carboxyphenyl)porphyrin and lanthanide ions in crystalline solids, Dalton Trans. 30 (2007) 3273-3281.

39. M. La Deda, M. Ghedini, I. Aiello, I. De Franco, Zinc porphyrin with phenoxy-bridged pentacoordinate bis (8hydroxyquinaldinate)gallium lateral pendants: synthesis and photophysical characterization, Inorg. Chem. Comm. 7 (2004) 1273-1276.

40. D.L. Akins, S. Özcelik, H.R. Zhu, C. Guo, Fluorescence decay kinetics and structure of aggregated tetrakis(psulfonatophenyl)porphyrin, J. Phys. Chem. 100 (1996) 14390-14396. 